\title{
Unpaid Caring Within and Outside the Carer's Home in England and Wales
}

\author{
Paul Norman ${ }^{1, *}$ and Kingsley Purdam ${ }^{2}$ \\ ${ }^{1}$ School of Geography, University of Leeds, Woodhouse Lane, Leeds, UK \\ ${ }^{2}$ Cathie Marsh Centre for Census and Survey Research, Humanities Bridgeford Street, University of Manchester, \\ UK
}

\section{ABSTRACT}

Unpaid caring is defined as any help or support provided to family members, friends, neighbours, or others because of their long-term physical or mental health or disability, or problems related to old age. It is estimated that there are over 5.2 million unpaid carers in England and Wales (2001 Census). Using the Small Area Microdata from the 2001 Census Samples of Anonymised Records, we examine geographic and socio-demographic variations in unpaid caring across England and Wales at local authority level with a particular focus on carers aged 40 years and older, comparing those who provide unpaid care within their own household and outside their household. The distinction between care within and outside the household is based on whether or not the carer lived with a co-resident reporting a limiting long-term illness.

We find a strong geographical relationship between levels of illness and of unpaid care. However, when this is disaggregated by whether the care is provided within or outside the household, we find that care away from the home is likely to be outside the geographical area in which the carer lives. Our individual level analyses suggest associations between rates of unpaid caring and a person's age, gender, ethnicity, social class, and the carer's own health status. Moreover, these relationships are different for people who provide care within or outside their own household.

Our findings have important implications for our understanding of the dynamics of caring and for service providers at a national and local

*Correspondence to: Paul Norman, School of Geography, University of Leeds, Woodhouse Lane, Leeds, LS2 9JT, UK. E-mail: p.d.norman@leeds.ac.uk level and also for government focus on independent living for people with social care needs and those in later old age. Unpaid carers who do not live with people they care for are likely to face different demands. Support is needed both for themselves and for the people whom they care. Copyright (C) 2012 John Wiley \& Sons, Ltd.

Accepted 23 December 2011

Keywords: unpaid care; informal care; UK Census; Sample of Anonymised Records; Small Area Microdata

\section{INTRODUCTION}

$\mathrm{U}$ npaid caring is defined as any help or support provided to family members, friends, neighbours, or others because of their long-term physical or mental health or disability, or problems related to old age. The 2001 Census found that there are over 5.2 million unpaid carers in England and Wales of whom 1.6 million persons provide $20 \mathrm{~h}$ or more care per week. Around one in five households in Britain have at least one person who is an unpaid carer (Maher and Green, 2002; Carers UK, 2009).

In this paper, we examine geographic and socio-demographic variations in the amount of unpaid caring at the local authority level and compare unpaid caring that takes place within the unpaid carer's home and outside their home. Using the Small Area Microdata (SAM) from the 2001 Census Samples of Anonymised Records Samples of Anonymised Records (SARs), we investigate subnational, geographical, and social variations in unpaid caring in England and Wales. Our focus is on the question of who is doing the unpaid caring in terms of age, gender, 
ethnic group, social class and housing type, and whether unpaid caring varies geographically. We make a distinction in terms of whether an unpaid carer provides care within or outside their own household because there might be different geographies and characteristics of carers. This distinction is based on whether or not the carer lived with a co-resident reporting a limiting long-term illness (LLTI).

The primary statutory responsibility for caring for people in need in England and Wales lies with the local authority (LA) in which the person lives and specifically the social services department. The care itself is however often delivered by a range of partners and service providers across the public, private, and voluntary sector. LAs in England and Wales use a national framework from the Department of Health $(2010 a, 2010 b)$ to decide the eligibility criteria for the adult social care services it provides. LAs assess care according to four eligibility bands - critical, substantial, moderate, and low. Critical refers to an idea that someone's life is or will be threatened; low refers to an inability to carry out one or two personal care or domestic routines; and/or involvement in one or two aspects of work, education, or learning cannot or will not be sustained. In the context of an economic recession in the UK and reductions in public spending care assessment is under review both nationally and at a local authority level. Moreover, there is a further ongoing review of how social care will be funded.

\section{Who are the Unpaid Carers in England and Wales?}

Unpaid caring is a crucial aspect of the welfare infrastructure of England and Wales. Using the General Household Survey, Maher and Green (2002) found that just over half of unpaid carers were looking after a parent, $18 \%$ were caring for their spouse or partner, and $8 \%$ for their child. There were $62 \%$ of unpaid carers caring for someone with a physical disability, and 18\% caring for someone with both mental and physical disability. In terms of the type of help, $26 \%$ of unpaid carers reported providing help with personal care, $71 \%$ providing practical help such as cooking and shopping, 55\% providing company, and $22 \%$ administering medicines. The economic value of unpaid care has been estimated by Buckner and Yeandle (2007) who suggest that unpaid caring is equivalent to $£ 87$ billion of paid work, which is equivalent to $£ 15,200$ for every carer.

Informal caregiving is found to be systematically linked with both age and gender (Maher and Green, 2002; Dahlberg et al., 2007). Overall, women are more likely to be unpaid carers than men, with $20 \%$ of women aged between 60 and 64 years being unpaid carers. Amongst the 'older old' (aged 75 years and older), this changes, and men are more likely to be carers (Buckner and Yeandle, 2005; Young et al., 2005). Generally, as an unpaid carer's age increases, so does the amount of care they provide. Over 8,000 unpaid carers are aged 90 years and older; 4,000 of these carers provide $50 \mathrm{~h}$ or more care each week. According to the 2001 Census, there are around 229,300 young adult unpaid carers aged 18-24 years. For further discussion, see the studies of Becker and Becker (2008) and Dearden and Becker, 2004).

Although there is a need to account for individual preferences in relation to care needs and choices, it is important to understand what shapes these preferences. It is notable that a survey of carers who are also in employment (aged 25-64 years) highlighted that a substantial proportion of respondents in England (35\%) said that they and the person they were supporting were not receiving any formal care service support (Yeandle et al., 2007). The authors argue that these access issues cannot be attributed to very low levels of care need, as the survey respondents were mostly unpaid carers with 'heavy' caring responsibilities. The unpaid carers stated that the main factors limiting the use of services were as follows: services were not flexible enough (almost half of all unpaid carers), not sensitive enough to needs (44\%), and the person cared for did not want to use services (44\%). Over a third of unpaid carers stated that their use of services was constrained because they did not know what was available locally. The Mental Capacity Act 2005 protects an individual's right to decide their own care whereby people should be given as much help as possible to make their own decisions.

At the local authority level, there is a correlation between levels of unpaid caring and deprivation, and a strong association between the level of unpaid caring and the level of LLTI after standardising for age, gender, health, and socio-economic status (Hutton and Hirst, 2000; Shaw and Dorling, 2004; Young et al., 2005, 2006). 
Evidence also suggests that there are variations in the levels of unpaid caring by different ethnic groups. After controlling for age, sex, and socio-economic variables, Young et al. (2005) identified strong differences by ethnicity in the propensity to provide unpaid care. Bangladeshi, Pakistani, and Indian populations were found to be significantly more likely to provide unpaid care than the White population (see also Maher and Green, 2002). This may be a result of different traditions regarding extended families but may reflect a lack of access to state funded care. The first generation of South Asian migrants to the UK (mainly to England) in the post-war period are now entering older age, which raises a number of issues in relation to access to and the availability of culturally sensitive care provision.

Caring for another person within or outside a person's own home is likely to raise different challenges both for the carer and the person being cared for. Maher and Green (2002) found using the General Household Survey that around a third of unpaid carers were looking after someone in their own home, whereas two-thirds were caring for someone outside the carer's home. There were $63 \%$ of those people providing unpaid care for someone in their own home provided more than $20 \mathrm{~h}$ per week of unpaid care compared with $11 \%$ of those providing care for someone outside their own home. Those people caring for someone outside their home were more likely to be caring for elderly relatives or friends. They found that those caring for someone in their own household were more likely to provide help with personal and physical tasks. Maher and Green (2002) also found that those people who lived with their unpaid carer were less likely to be receiving support from health, social, and voluntary services compared with those people who were living in a different household from their carer. It is believed that one in five unpaid carers has given up work to provide care, especially women (Carers UK, 2009). Providing unpaid care can lead to the deteriorating health of the carer with poor health independently associated with unpaid care provision after controlling for socioeconomic factors (Maher and Green 2002; Young et al., 2005).

Only limited research has been conducted, which compares unpaid caring within and outside the carers home at local authority level. In this paper, for England and Wales, we compare those who provide unpaid care within or outside their own home and consider how such caring varies in terms of geography and individual social circumstances. To establish overall levels of care provided and to investigate geographical variations in caring, we include all persons aged 16 years and older. At individual level, we focus in particular on carers aged 40 years and older because these persons provide the majority of care and on those persons who are carrying out $20 \mathrm{~h}$ or more per week caring for somebody because this represents a substantial time commitment.

\section{DATA AND METHODOLOGY}

We draw on evidence from the UK's 2001 Census SARs, a dataset, which allow users to carry out flexible, multivariate analysis at the level of the individual (Dale et al., 2000). SARs were extracted from the 2001 Census and include the SAM, a 5\% sample of individuals for all countries in the UK, with 2.96 million cases and with the local authority of each respondent included. Here, we use the SAM for England and Wales because this individual level dataset allows both geographical and social dimensions to be investigated.

\section{Key Variables}

\section{Unpaid caring and health}

The 2001 Census included a question on unpaid care, which enables the examination of variations in levels of care by the amount of time spent as well as subnational variations. The 2001 Census also asked all respondents whether they have a LLTI. The question wordings are stated in Box 1. The answers to these questions that are included in the SAM allow us to determine whether a person is an unpaid carer, how much care they provide, and whether somebody in the household has a long-term illness.

Although not explicitly asked in the Census, for the dynamics of unpaid caring to be captured, the SAM allows us to differentiate between unpaid carers who live with someone who has a LLTI within their household and those who do not. In our research, this differentiation allows us to distinguish between people who provide unpaid care within their household and those who provide unpaid care outside their household. A similar approach has been used very effectively with the Office National Statistics 
Box 1. 2001 Census questions on 'Unpaid Care' and 'Limiting Long-Term Illness'

Topic
Whether a person is an unpaid carer and how
much care they provide

Whether there is someone in the household who has long-term limiting illness
2001 Census Question

Q12. Respondents are asked: "Do you look after, or give any help or support to family members, friends, neighbours or others because of: long-term physical or mental ill-health or disability, or problems related to old age.

If so, respondents were asked to indicate whether the time spent in a typical week was 1-19 hours, 20-49 hours or 50+ hours. Caring provided as part of paid employment was not to be included

Q13. Respondents are asked: "Do you have a long-term illness, health problem or disability which limits your daily activity or the work you can do? Include problems which are due to old age.

This question was asked of each person in the household and it is therefore possible to identify if there is a person in the household who has a long-term illness

Source: UK 2001 Census

(ONS) Longitudinal Study for England and Wales by Young et al. (2006: 4) to identify those who they term the 'presumed care recipient.'

It is, however, important to note that people who are providing unpaid care who live with a person with a long-term health problem could also be providing care to someone else outside their own household. With the available data, we cannot capture this, so might be underestimating levels of care provided away from the carer's own home.

\section{Geography}

For England and Wales, we utilise the local authority geography included in the SAM to allow us to investigate ecological relationships between levels of LLTI and care, both inside and outside the carer's household. In 2001, there were 376 local authorities in England and Wales, but in the SAM, there are 374 because records for the City of London have been combined with Westminster and those for the Isles of Scilly have been combined with Penwith in Cornwall. We also use the Government Office Region (GOR) of residence. Because demographic-related activities vary by area type (e.g. Norman and Bambra, 2007; Stillwell et al., 2008; Norman, 2010), we use the ONS 'Supergroups' (Vickers and Rees, 2006) as a means to characterise areas.

For geographical analyses, we aggregate the individual records in the SAM into the local authorities in which people live and relate levels of unpaid care provided with levels of LLTI. We report correlations between $20 \mathrm{~h}$ or more per week of care and LLTI and then subdivide the care into that provided within and outside the carer's own household. We also aggregate the individual records into Government Office Regions and into ONS Supergroups to investigate whether there are patterns for these geographies.

For individual level analyses, we use logistic regression (Dale et al., 2000: 165) with the binary outcome of whether or not a person provides $20 \mathrm{~h}$ or more per week of unpaid care. For this level of extended care time, three models are reported with outcomes of (i) care, (ii) care provided within the carer's home, and (iii) care outside the carer's home. In each model, a subset of the SAM is used to create a study sample, which comprises non-carers and persons who provide the care of the outcome specified (so other care outcomes are excluded).

The explanatory variables included in the logistic regression models are detailed in the following paragraphs but include age group, gender, ethnic group, social class, educational achievement, accommodation type, tenure, marital status, general health, and access to car as well as the geographical variables noted previously. The models are reported using odds ratios (to show how different categories within each variable have different propensities to care compared with a reference category). Later in the discussion section, for clarity, we convert the odds to probabilities (Dale et al., 2000: 174; Boyle et al., 2002: 24). 


\section{ANALYSIS AND RESULTS}

\section{Geographical Variations in Unpaid Caring}

Across England and Wales, at local authority level, we identify a strong positive association between the percentage of persons providing unpaid care and levels of LLTI in an area $(r=0.69$; $p<0.001)$. This finding is consistent with research by Shaw and Dorling (2004) and others. Generally then, as would be expected, where there are more people with a LLTI, there are more people providing unpaid care. This is not the complete picture however.

When we consider the relationship between area levels of LLTI and the percentage of persons providing unpaid care within their household, we find a much stronger positive correlation $(r=0.91$; $p<0.001$ ). For the relationship between LLTI and unpaid caring being provided outside the person's household, we find that the relationship is reversed as the correlation is negative $(r=-0.33$, $p<0.001)$. This suggests that to some degree, there is a different geography for people providing unpaid caring outside the household compared with those providing unpaid caring within their household. The implication of the change in the correlation from positive to negative is that it is possible that much of the unpaid caring outside the household occurs in a different local authority to where the carer is resident.

In terms of variations across the local authorities in England and Wales, of all persons aged 16 years and older the overall percentages of those providing unpaid care vary between $8 \%$ (Wandsworth) and $17 \%$ (Neath Port Talbot) compared with the England and Wales average of $12.5 \%$. Levels of unpaid care are highest in former industrial areas, particularly in local authorities in Wales. Of all persons aged 16 years and older, the percentages of those who provide unpaid care within their household vary between 3.7\% (Kensington and Chelsea) and 12\% (Neath Port Talbot again) compared with the England and Wales' average of just over $7 \%$. The equivalent figures for those who provide unpaid care outside their household are $3.6 \%$ in Lambeth and $7.8 \%$ in Chiltern, with an average across England and Wales of 5.5\%.

In the main, more people provide unpaid care for a person within their own household, but in 74 local authorities, there are larger percentages of people providing unpaid care outside their household. These local authorities are mainly in London and the south-east. As noted previously, the ONS Supergroups (Vickers and Rees, 2006) can be used to analyse results by type of areas. Sixty-five of the 74 local authorities are classified as being of the Prosperous UK area type. Because this represents over $40 \%$ of the local authorities in this Supergroup, this leads us to suggest that unpaid caring is being carried out differently in these areas.

Because there appear to be regional and area type variations in the levels of unpaid caring, it is useful to summarise by aggregating measures by Government Office Region and by ONS Supergroup. Figure 1(a) illustrates the percentage of care provided along with the percentage of persons reporting LLTI. As would be expected, there is a clear relationship between levels of illness and unpaid care provided with the highest levels of both in the GORs, which include former industrial areas especially the north-east and Wales. Given their apparent health advantage, levels of unpaid care are relatively high in the south-east and in the east of England. The lowest levels of unpaid care are in London.

Figure 1(b) shows levels of LLTI and unpaid care by ONS Supergroup. Similar to the GORs, the area types with the higher levels of LLTI also have higher levels of unpaid care being provided, particularly in Mining \& Manufacturing areas. Although levels of LLTI vary little across the area types within London and those LAs classified as Prospering UK, the levels of unpaid care provided are somewhat different. Higher percentages of care are shown in London Suburbs and Prospering UK than in the LAs classified as London Centre and in London Cosmopolitan.

As we have found an indication of different geographies of unpaid caring by whether the caring is carried within or outside the carer's household, we differentiate the percentages of care across the GORs and Supergroups. We also provide 'in-to-out' ratios to highlight whether the balance varies geographically (a ratio of above 1 indicates more care inside than outside the home). Figure 2(a) shows that the poorer health areas tend to have a predominance of caring within the carer's home, particularly in Wales. The better health areas tend to have levels of care circumstance more similar especially in the east of England and the south-east where the in-to-out ratios are nearing 1. 


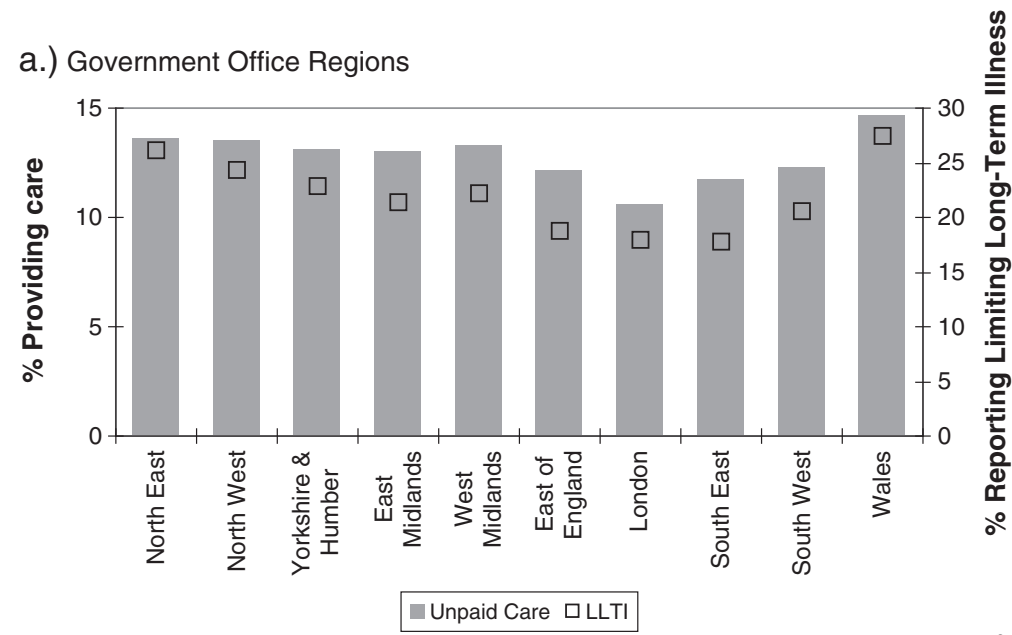

b.) ONS Supergroups

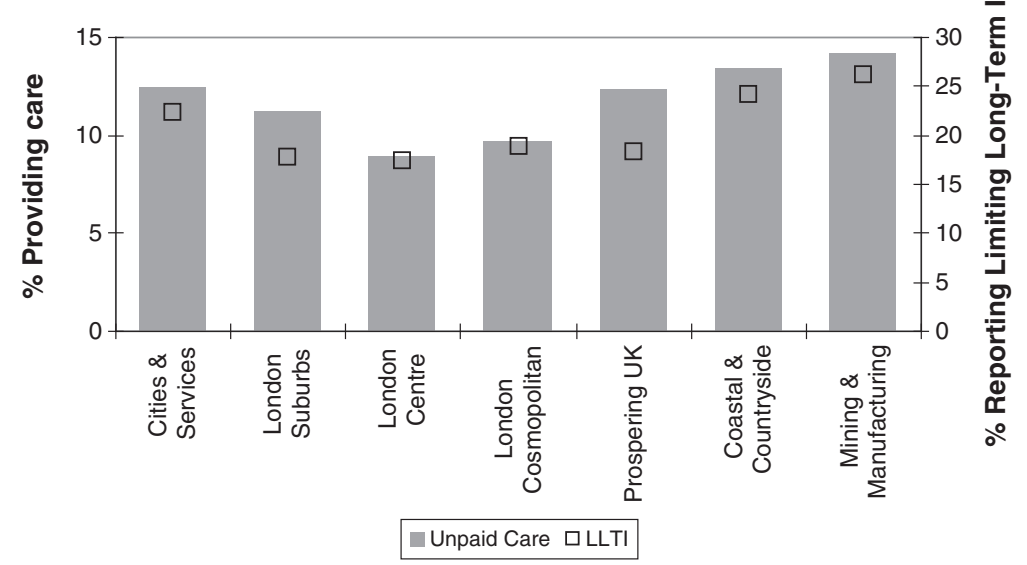

Note: Authors' calculations based on 2001 Census Small Area Microdata

Figure 1. Variations in limiting long-term illness and the provision of unpaid care by Government Office Region and Office National Statistics (ONS) Supergroup: England and Wales, 2001.

For the Supergroups, Figure 2(b) reveals a similar situation with the poorer health area types, particularly Mining \& Manufacturing areas have a large proportion of the unpaid care provided within the home. Different care location circumstances are shown for the Supergroups within London. The areas classified as Cosmopolitan have a greater proportion of care provided within the home than in London Suburbs or London Centre in which the level of care provided outside the household is closer to that within the home. Prospering UK areas have in-to-out ratios near 1, indicating very similar levels of unpaid care provided within and outside the carer's household.

In the main, geographical levels of unpaid care have a strong relationship with levels of LLTI. It would appear, however, that in areas where health is particularly poor, there is relatively more care being carried out within the carer's own home, whereas in better health areas, care is provided at more similar levels within and outside the household. Because classifications such as the ONS Supergroups reflect geographic concentrations of persons with similar characteristics, we next investigate socio-demographic associations with care provision.

\section{Socio-demographic Variations in Unpaid Caring}

Here, we examine a subpopulation of those aged 40 years and older, focusing on the carers who 
a.) Government Office Regions

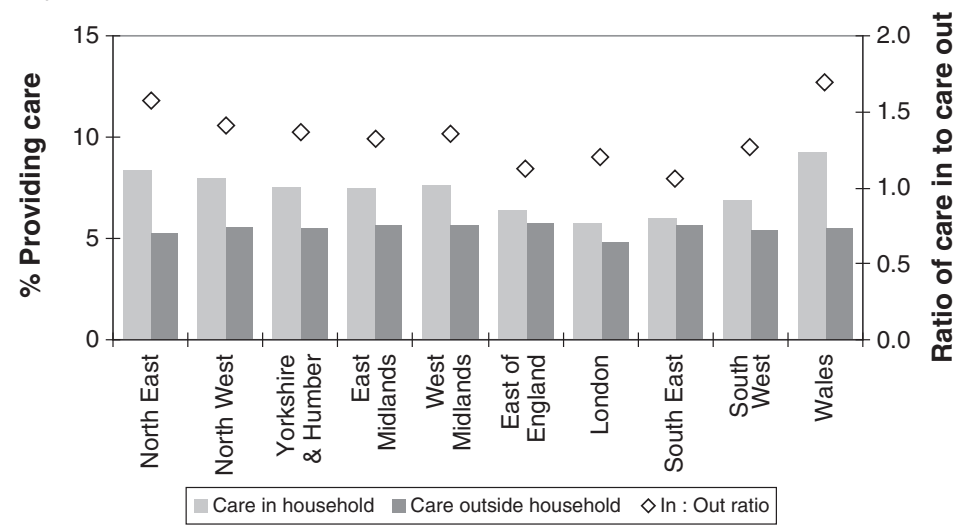

b.) ONS Supergroups

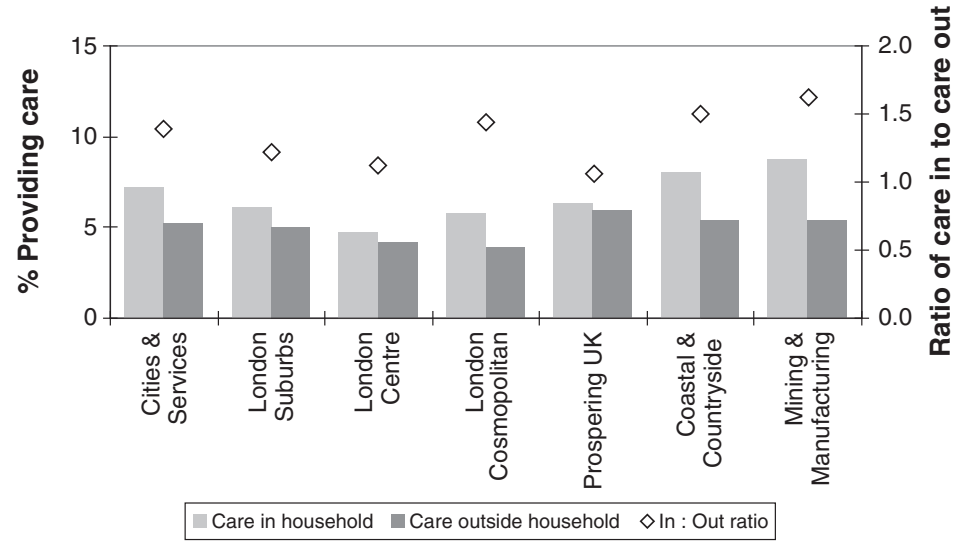

Note: Authors' calculations based on 2001 Census Small Area Microdata. The distinction between care within and outside the household is based on whether or not the carer lived with a co-resident reporting a limiting long-term illness

Figure 2. Variations in limiting long-term illness and the provision of unpaid care within and outside the carer's household by Government Office Region and Office National Statistics (ONS) Supergroup: England and Wales, 2001.

provide $20 \mathrm{~h}$ and more per week of unpaid care. After initial descriptive statistics we develop a series of models that investigate the propensity for people to provide $20 \mathrm{~h}$ or more per week of unpaid care for someone within or outside their household. We control in these models for a range of socio-demographic characteristics and for geographical variables, as identified previously.

This study sample comprises nearly 1.2 million persons aged 40 years and older, present in England and Wales in the 2001 Census over 5\% of whom provide unpaid care for more than $20 \mathrm{~h}$ per week. Figure 3(a) shows the age profile of carers. For both men and women, there is an increase with age in the percentage providing unpaid care from age 40-49 years to those aged 50-59 years; after which, the rate declines. For all age groups, except those aged 75 years and older, the percentage of women providing unpaid care is greater than for men. These findings may reflect longer female life expectancy. Where men do survive to older ages, they are probably providing unpaid care for a partner. Bono et al. (2009) have highlighted that differences in the level of unpaid caring amongst older people are largely explained by gender differences in marital status. Older men are more likely to be married, and people who are married are more likely to be unpaid carers. There are large numbers of unpaid carers who are older men (see Young et al., 2006).

Figure 3(b) illustrates the percentages of persons providing $20 \mathrm{~h}$ or more per week of care by ethnic group. The Indian and Pakistani, and 
a.) Unpaid care by age and gender

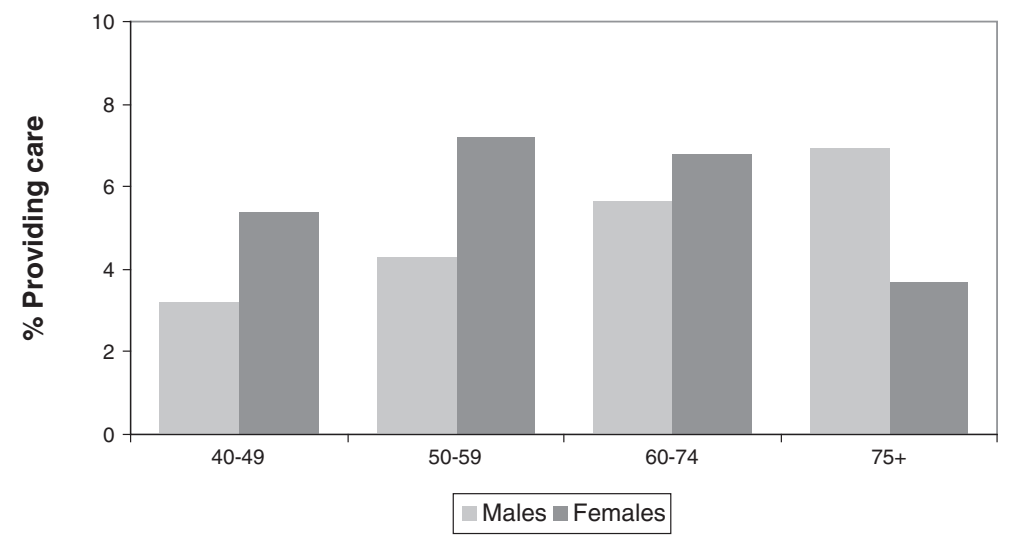

b.) Unpaid care by ethnic group

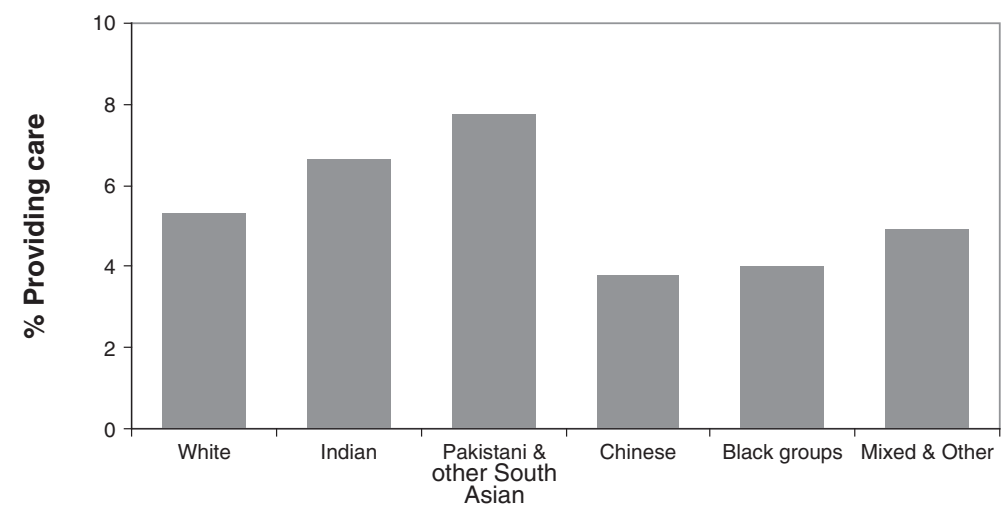

Source: Authors' calculations based on 2001 Census Small Area Microdata

Figure 3. Levels of unpaid caring for $20 \mathrm{~h}$ and more per week by age, gender, and ethnic group: England and Wales, 2001.

other South Asian groups have higher percentages of persons providing care than the White group. The Chinese, Black, and other groups have lower percentages of persons providing unpaid care. These differences are consistent with previous work (Young et al., 2006).

\section{Propensity to Provide $20 \mathrm{~h}$ or More of Unpaid Care per Week}

Our first model investigates the provision of extended hours of care with no differentiation for the location of the care. Here, we control for gender, age, ethnic group and the geographical variables ONS Supergroup, and Government Office Region. Table 1 shows the odds ratios and confidence intervals. Women are shown to be significantly more likely to provide care than men, and the age pattern is that, compared with the reference category $40-49$ years, those in the next two oldest age groups are more likely to provide extended care. Persons aged 75 years and older provide care at similar levels to those aged 40-49 years. The likelihood of persons of South Asian origin providing extended care is significantly greater than for the White group. The Chinese and Black groups are less likely than the White group, but for the mixed and other group, there is no difference in the odds of providing care.

Compared with the reference level Supergroup, Cities \& Services, only those persons in Mining \& Manufacturing areas are significantly more likely to provide extended care. London Centre and Prospering UK are significantly less likely to provide care than the reference category, but for London Suburbs and London Cosmopolitan, there is no difference. For the Government Office 
Table 1. Likelihood of persons aged 40 years and older providing $20 \mathrm{~h}$ or more per week unpaid care.

\begin{tabular}{|c|c|c|c|c|}
\hline Variable & Categories & Odds ratio & Lower CI & Upper CI \\
\hline \multirow[t]{2}{*}{ Gender } & Male (ref.) & 1.00 & & \\
\hline & Female & 1.33 & $(1.31$ & $1.35)$ \\
\hline \multirow[t]{4}{*}{ Age group (years) } & $40-49$ (ref.) & 1.00 & & \\
\hline & $50-59$ & 1.44 & $(1.40$ & 1.47) \\
\hline & $60-74$ & 1.44 & $(1.41$ & 1.47) \\
\hline & $75+$ & 1.03 & $(1.00$ & $1.06)$ \\
\hline \multirow[t]{6}{*}{ Ethnic group } & White (ref.) & 1.00 & & \\
\hline & Indian & 1.30 & $(1.23$ & 1.39) \\
\hline & Pakistani and other South Asian & 1.48 & $(1.39$ & 1.58) \\
\hline & Chinese & 0.71 & $(0.60$ & $0.84)$ \\
\hline & Black groups & 0.75 & $(0.69$ & $0.82)$ \\
\hline & Mixed and others & 0.96 & $(0.87$ & 1.06) \\
\hline \multirow[t]{7}{*}{ ONS Supergroup } & Cities \& Services (ref.) & 1.00 & & \\
\hline & London Suburbs & 1.01 & $(0.96$ & 1.07) \\
\hline & London Centre & 0.88 & $(0.82$ & $0.95)$ \\
\hline & London Cosmopolitan & 1.02 & $(0.97$ & 1.07) \\
\hline & Prospering UK & 0.84 & $(0.82$ & $0.86)$ \\
\hline & Coastal \& Countryside & 0.95 & $(0.92$ & $0.99)$ \\
\hline & Mining \& Manufacturing & 1.13 & $(1.10$ & 1.16) \\
\hline \multirow[t]{10}{*}{ Government Office Region } & North-East (ref.) & 1.00 & & \\
\hline & North-West & 1.00 & $(0.96$ & 1.04) \\
\hline & Yorkshire and Humber & 0.93 & $(0.89$ & $0.97)$ \\
\hline & East Midlands & 0.89 & $(0.85$ & $0.93)$ \\
\hline & West Midlands & 0.98 & $(0.94$ & 1.02) \\
\hline & East of England & 0.83 & $(0.79$ & $0.87)$ \\
\hline & London & 0.78 & $(0.74$ & $0.82)$ \\
\hline & South-East & 0.75 & $(0.72$ & $0.78)$ \\
\hline & South-West & 0.85 & $(0.81$ & $0.89)$ \\
\hline & Wales & 1.18 & $(1.13$ & 1.23) \\
\hline
\end{tabular}

Source: 2001 Census Small Area Microdata.

The table displays the odds ratios (and 95\% CI) of providing unpaid care.

The likelihood of care is contrasted with people who do not provide care and with other caring categories excluded.

Categories of variables, which are not significantly different to the reference category, are in italics.

CI, confidence intervals; ONS, Office National Statistics.

Regions, only persons in Wales have greater odds of providing extended care than persons in the north-east. The North-West and West Midlands have similar levels of caring to the north-east. All other GORs have odds ratios of less than one, indicating lower levels of unpaid care provision than the North-East.

\section{Within the Carer's Household: Propensity to Provide $20 \mathrm{~h}$ or More of Unpaid Care per Week}

Our second model focuses on those who provide extended levels of unpaid care within their own household compared with persons who do not provide care. Other caring categories, less than $20 \mathrm{~h}$ per week and care outside the household, are excluded. In addition to age, gender, and ethnicity, we now include a range of sociodemographic variables (social class, educational achievement, accommodation type, tenure, marital status, general health, access to car) as well as the geographical variables used previously.

As before, Table 2 shows that women are more likely to provide care than men. An increase in likelihood with age is found, but in this model, those aged 75 years and older are more likely to provide care compared with persons aged $40-49$ years. This is probably care provided by men of this age group, but a model with the interaction of gender and age had non-significant combinations. The difference between the White group and the South Asians is attenuated with 
Table 2. Likelihood of persons aged 40 years and older providing $20 \mathrm{~h}$ or more per week unpaid care within the household.

\begin{tabular}{|c|c|c|c|c|}
\hline Variable & Category & Odds ratio & Lower CI & Upper CI \\
\hline \multirow[t]{2}{*}{ Gender } & Male (ref.) & 1.00 & & \\
\hline & Female & 1.31 & $(1.28$ & 1.33) \\
\hline \multirow[t]{4}{*}{ Age group (years) } & $40-49$ & 1.00 & & \\
\hline & $50-59$ & 1.50 & $(1.46$ & 1.54) \\
\hline & $60-74$ & 1.26 & $(1.22$ & 1.30) \\
\hline & $75+$ & 1.12 & $(1.08$ & $1.17)$ \\
\hline \multirow[t]{6}{*}{ Ethnic group } & White (ref.) & 1.00 & & \\
\hline & Indian & 1.13 & $(1.06$ & 1.21) \\
\hline & Pakistani and other South Asian & 0.94 & $(0.88$ & 1.01) \\
\hline & Chinese & 0.51 & $(0.41$ & $0.63)$ \\
\hline & Black groups & 0.56 & $(0.51$ & $0.62)$ \\
\hline & Mixed and others & 0.84 & $(0.75$ & $0.94)$ \\
\hline \multirow[t]{8}{*}{ NS-SEC } & Large employers and higher professionals (ref.) & 1.00 & & \\
\hline & Lower managerial and professionals & 1.39 & $(1.31$ & 1.48) \\
\hline & Intermediate occupations & 1.45 & $(1.36$ & 1.56) \\
\hline & Small employers and own account workers & 1.44 & $(1.35$ & 1.54) \\
\hline & Lower supervisory and technical occupations & 1.68 & $(1.57$ & $1.80)$ \\
\hline & Semi-routine & 1.77 & $(1.66$ & $1.89)$ \\
\hline & Routine occupations & 1.71 & $(1.60$ & 1.83) \\
\hline & Never worked and long-term employed & 2.98 & $(2.81$ & 3.17) \\
\hline \multirow[t]{5}{*}{ Educational achievement } & No qualifications (ref.) & 1.00 & & \\
\hline & Level 1 & 0.95 & $(0.92$ & $0.98)$ \\
\hline & Level 2 & 0.96 & $(0.93$ & $0.99)$ \\
\hline & Level 3 & 0.93 & $(0.89$ & $0.99)$ \\
\hline & Level 4/5 & 0.83 & $(0.81$ & $0.86)$ \\
\hline \multirow[t]{3}{*}{ Tenure of accommodation } & Owner occupiers (ref.) & 1.00 & & \\
\hline & Public rented & 1.00 & $(1.50$ & 1.58) \\
\hline & Private rented & 1.15 & $(1.11$ & 1.19) \\
\hline \multirow[t]{3}{*}{ Accommodation type } & Detached or semi-detached & 1.00 & & \\
\hline & Terraced house & 1.08 & $(1.06$ & 1.10) \\
\hline & Flat & 0.99 & $(0.96$ & 1.03 \\
\hline \multirow[t]{3}{*}{ Marital Status } & Single (never married) (ref.) & 1.00 & & \\
\hline & Married/re-married & 0.70 & $(0.67$ & $0.73)$ \\
\hline & Separated/divorced/widowed & 0.33 & $(0.31$ & $0.34)$ \\
\hline \multirow[t]{2}{*}{ Access to car } & Has access to car (ref.) & 1.00 & & \\
\hline & No access to car & 1.12 & $(1.09$ & 1.15) \\
\hline \multirow[t]{2}{*}{ General health } & Good health (ref.) & 1.00 & & \\
\hline & Poor or bad health & 1.69 & $(1.66$ & 1.72) \\
\hline \multirow[t]{7}{*}{ ONS Supergroup } & Cities \& Services (ref.) & 1.00 & & \\
\hline & London Suburbs & 1.02 & $(0.96$ & 1.09) \\
\hline & London Centre & 0.86 & $(0.79$ & $0.93)$ \\
\hline & London Cosmopolitan & 0.95 & $(0.90$ & 1.00) \\
\hline & Prospering UK & 0.89 & $(0.87$ & $0.91)$ \\
\hline & Coastal \& Countryside & 1.02 & $(0.98$ & $1.06)$ \\
\hline & Mining \& Manufacturing & 1.10 & $(1.07$ & $1.13)$ \\
\hline \multirow[t]{6}{*}{ Government Office Region } & North-East (ref.) & 1.00 & & \\
\hline & North-West & 1.06 & $(1.01$ & 1.10) \\
\hline & Yorkshire and Humber & 0.99 & $(0.95$ & $1.04)$ \\
\hline & East Midlands & 0.98 & $(0.93$ & 1.03) \\
\hline & West Midlands & 1.04 & $(0.99$ & 1.09) \\
\hline & East of England & 0.90 & $(0.85$ & $0.94)$ \\
\hline
\end{tabular}


Table 2. (Continued)

\begin{tabular}{|c|c|c|c|c|}
\hline Variable & Category & Odds ratio & Lower CI & Upper CI \\
\hline & London & 0.86 & (0.81 & $0.92)$ \\
\hline & South-East & 0.86 & $(0.82$ & $0.90)$ \\
\hline & South-West & 0.95 & $(0.90$ & 1.00) \\
\hline & Wales & 1.24 & (1.18 & 1.30) \\
\hline
\end{tabular}

Source: 2001 Census Small Area Microdata.

The table displays the odds ratios (and 95\% CI) of providing unpaid care.

The likelihood of care is contrasted with people who do not provide care and with other caring categories excluded.

Categories of variables which are not significantly different to the reference category are in italics.

The distinction between care within and outside the household is based on whether or not the carer lived with a co-resident reporting a limiting longterm illness.

CI, confidence intervals; ONS, Office National Statistics; NS-SEC, Statistics Socio-Economic Classification.

just the Indian group more likely to provide care. This suggests that the differences in the provision of care within the home are largely accounted for by other socio-demographic characteristics. As before, the non-South Asian ethnic groups are less likely to provide care than the White group.

Social Class and educational achievement are both included in this model. The measure of social class we use is the National Statistics Socio-Economic Classification (NS-SEC). In relation to unpaid caring within the household, the odds of providing unpaid care gradually increase as the categories of NS-SEC move away from the 'large employers and higher professionals' and to the less skilled and routine occupations. The majority of caring within the household would appear to be provided by persons of lower NS-SEC categories. ${ }^{1}$ Consistent with the relationship between the propensity to provide care and NS-SEC, compared with those persons with no qualifications, persons with increasingly higher educational achievement are less likely to provide unpaid care.

The household tenure, accommodation type, and people's marital status may affect where the care is provided. In terms of tenure, persons living in public or private rental property are more likely to provide unpaid care within the home than owner occupiers. Perhaps this reflects ability to pay for formal care because we would expect persons as owner occupiers to be financially better off than people who rent their home. Persons in terraced housing are slightly more likely to provide care within the home than those people living in detached or semi-detached housing. Those living in flats are less likely to provide care, which perhaps relates to lack of space, although the difference is not significant.
In terms of marital status, compared with persons who are single, married, separated, divorced, or widowed are less likely to provide extended unpaid care within their household. Motivated by the findings of Bono et al. (2009), we investigated the interaction of gender and marital status, which suggested that men who were married, are slightly more likely to provide care, but the relationship is not significant.

Persons who do not have access to a car are more likely to provide unpaid care within their household, as are those carers who themselves are reporting poor of bad general health. Both of these relationships suggest a degree of immobility about the carers themselves, especially because they are carrying out over $20 \mathrm{~h}$ per week of caring.

The patterns by Government Office Region and ONS Supergroup are very similar to model 1 , which only otherwise includes variables about gender, age, and ethnic group. The GORs and Supergroups associated with poor health have higher odds of providing care than the better health areas, but the differences from the reference category are attenuated by the inclusion of the socio-demographic variables included here in model 2.

\section{Outside the Carer's Household: Propensity to Provide $20 \mathrm{~h}$ or More of Unpaid Care per Week}

The third model includes the same variables as model 2 but investigates the likelihood of people providing $20 \mathrm{~h}$ or more per week of unpaid care outside their own household (compared with those who do not provide care and with other care circumstances excluded). In this model (Table 3), women are more than twice as likely than men to 
Table 3. Likelihood of persons aged 40 years and older providing $20 \mathrm{~h}$ or more per week unpaid care outside the household.

\begin{tabular}{|c|c|c|c|c|}
\hline Variable & Category & Odds ratio & Lower CI & Upper CI \\
\hline \multirow[t]{2}{*}{ Gender } & Male (ref.) & 1.00 & & \\
\hline & Female & 2.21 & $(2.09$ & 2.33) \\
\hline \multirow[t]{4}{*}{ Age group } & 40-49 (ref.) & 1.00 & & \\
\hline & $50-59$ & 1.36 & $(1.28$ & 1.44) \\
\hline & $60-74$ & 0.65 & $(0.60$ & $0.71)$ \\
\hline & $75+$ & 0.23 & $(0.20$ & $0.27)$ \\
\hline \multirow[t]{6}{*}{ Ethnic group } & White (ref.) & 1.00 & & \\
\hline & Indian & 1.31 & $(1.11$ & 1.54) \\
\hline & Pakistani and other South Asian & 1.83 & $(1.56$ & 2.14) \\
\hline & Chinese & 1.46 & $(1.07$ & 1.99) \\
\hline & Black groups & 1.27 & $(1.08$ & 1.49) \\
\hline & Mixed and others & 1.14 & $(0.91$ & 1.43) \\
\hline \multirow[t]{8}{*}{ NS-SEC } & Large employers and higher professionals (ref.) & 1.00 & & \\
\hline & Lower managerial and professionals & 1.25 & $(1.11$ & 1.42) \\
\hline & Intermediate occupations & 1.21 & $(1.06$ & 1.39) \\
\hline & Small employers and own account workers & 1.50 & $(1.31$ & 1.72) \\
\hline & Lower supervisory and technical occupations & 1.47 & $(1.26$ & 1.70) \\
\hline & Semi-routine & 1.70 & $(1.50$ & 1.94) \\
\hline & Routine occupations & 1.46 & $(1.27$ & 1.68) \\
\hline & Never worked and long-term employed & 1.48 & $(1.30$ & 1.68) \\
\hline \multirow[t]{5}{*}{ Educational achievement } & No qualifications (ref.) & 1.00 & & \\
\hline & Level 1 & 1.00 & $(0.93$ & 1.09) \\
\hline & Level 2 & 1.08 & $(1.00$ & 1.16) \\
\hline & Level 3 & 1.09 & $(0.97$ & 1.22) \\
\hline & Level $4 / 5$ & 0.97 & $(0.90$ & 1.05) \\
\hline \multirow[t]{3}{*}{ Tenure of accommodation } & Owner occupiers (ref.) & 1.00 & & \\
\hline & Public rented & 1.15 & $(1.07$ & 1.24) \\
\hline & Private rented & 1.06 & $(0.97$ & 1.17) \\
\hline \multirow{3}{*}{ Accommodation type } & Detached or semi-detached (ref.) & 1.00 & & \\
\hline & Terraced house & 1.00 & $(0.94$ & 1.06) \\
\hline & Flat & 1.05 & $(0.96$ & 1.14) \\
\hline \multirow[t]{3}{*}{ Marital Status } & Single (never married) (ref.) & 1.00 & & \\
\hline & Married/re-married & 1.20 & $(1.07$ & 1.35) \\
\hline & Separated/divorced/widowed & 0.76 & $(0.69$ & $0.83)$ \\
\hline \multirow[t]{2}{*}{ Access to car } & Has access to car (ref.) & 1.00 & & \\
\hline & No access to car & 0.76 & $(0.71$ & $0.82)$ \\
\hline \multirow[t]{2}{*}{ General health } & Good health (ref.) & 1.00 & & \\
\hline & Poor or bad health & 0.66 & $(0.63$ & $0.70)$ \\
\hline \multirow[t]{7}{*}{ ONS Supergroup } & Cities \& Services (ref.) & 1.00 & & \\
\hline & London Suburbs & 1.15 & $(1.00$ & 1.33) \\
\hline & London Centre & 1.09 & $(0.91$ & 1.31) \\
\hline & London Cosmopolitan & 1.08 & $(0.95$ & 1.24) \\
\hline & Prospering UK & 0.90 & $(0.83$ & $0.97)$ \\
\hline & Coastal \& Countryside & 0.88 & $(0.79$ & $0.99)$ \\
\hline & Mining \& Manufacturing & 1.07 & $(0.98$ & 1.16) \\
\hline \multirow[t]{7}{*}{ Government Office Region } & North-East (ref.) & 1.00 & & \\
\hline & North-West & 0.92 & $(0.82$ & 1.04) \\
\hline & Yorkshire and Humber & 0.82 & $(0.73$ & $0.93)$ \\
\hline & East Midlands & 0.73 & $(0.64$ & $0.83)$ \\
\hline & West Midlands & 0.88 & $(0.77$ & $1.00)$ \\
\hline & East of England & 0.75 & $(0.66$ & $0.86)$ \\
\hline & London & 0.80 & $(0.69$ & $0.93)$ \\
\hline
\end{tabular}


Table 3. (Continued)

\begin{tabular}{llcccc}
\hline Variable & & Category & Odds ratio & Lower CI & Upper CI \\
\hline & South-East & 0.67 & $(0.58$ & $0.76)$ \\
& South-West & 0.72 & $(0.63$ & $0.83)$ \\
& Wales & 1.14 & $(1.00$ & $1.29)$ \\
\hline
\end{tabular}

Source: 2001 Census Small Area Microdata.

The table displays the odds ratios (and 95\% CI) of providing unpaid care.

The likelihood of care is contrasted with people who do not provide care and with other caring categories excluded.

Categories of variables that are not significantly different to the reference category are in italics.

The distinction between care within and outside the household is based on whether or not the carer lived with a co-resident reporting a limiting longterm illness.

CI, confidence intervals; ONS, Office National Statistics; NS-SEC, Statistics Socio-Economic Classification.

provide unpaid care, but although persons aged 50-59 years are more likely to provide care, the older two age groups are less likely, especially those aged 75 years and older. All ethnic groups (except mixed and others) are more likely than the White ethnic group to provide care outside their own household with the highest odds for the Pakistani and other South Asians.

Similar to the provision of care within the household, all other NS-SEC categories are more likely to provide care outside their own household than large employers and higher professionals. However, there is not a gradient from higher to lower NS-SEC categories with no significant difference between these. In terms of highest level of educational achievement, there is no apparent difference in the likelihood of providing care outside the household.

Tenure and accommodation type have little effect on the probability of providing care outside the carer's household. Those persons living in public-rented accommodation are more likely to provide care than owner occupiers, but for private renters, there is no significant difference. Persons living in the three accommodation types are no different in their propensities to provide care away from their home. Compared with persons who are single, those who are married are more likely to provide care outside their household but are less likely for the separated, divorced, or widowed (which could reflect lack of connection with others).

Access to a car and the carer's general health are likely to relate to their ability to be mobile to provide care away from their home. This seems to be the case because persons who have no access to a car are less likely to provide care. Similarly, those carers who are in poor health are less likely than those in good health to carry out extended care outside their own household.

Compared with persons living in the Cities \& Services area type, only those in London Suburbs are more likely to provide care away from their own household. Persons in Prospering UK and Coastal \& Countryside are less likely to carry out extended care outside the home. Within the GORs, persons in Wales are more likely to care outside the home than those living in the north-east. Although not all differences are significant, in the other regions, people are less likely to provide extended care, particularly in the South-East.

\section{DISCUSSION}

We have found here that geographical variations in levels of the provision of unpaid caring relate strongly to levels of LLTI. This is consistent with previous work by Shaw and Dorling (2004) and Young et al. $(2005,2006)$. When we focus on caring being carried out within the household, we find a stronger relationship. This is the case at both local authority and Government Office Region levels. When LAs are aggregated into ONS Supergroups, the area types associated with poor health have higher levels of unpaid care provided within the household. The weaker but negative relationship we find between the geographies of care provision and levels of LLTI suggest that to some degree, people are providing unpaid care away from the local authority in which they live. In good health areas, the provision of care inside and outside the home is at more similar levels than in poor health areas where care within the home predominates. A possible 
explanation then is that some people travel from good to poor health areas to provide care for friends or relatives who live in a different local authority.

As previous research has highlighted (Maher and Green 2002; Young et al., 2005, 2006), we find that for unpaid care provided within and outside their household, persons aged 50-59 years are significantly more likely to provide unpaid care than all other age groups. These age profiles are consistent with the scenario that persons aged 50-59 years are likely to be looking after elderly persons, perhaps their own parents. Women are significantly more likely to provide unpaid care than men in the unpaid care circumstances investigated here but with less difference when the unpaid care is provided within the household. The largest differences are when the unpaid care is provided outside the household when the burden of unpaid caring tends to fall on women. Using the General Household Survey, Maher and Green (2002) also found that women were more likely to be unpaid carers than men and that women were more likely to be providing unpaid care than men outside their household. Consistent with Dahlberg et al. (2007), it is notable that men aged 75 years and older provide a relatively high percentage of unpaid care. Here, we find that the majority of this care by elderly men is conducted within the home.

a.) Unpaid care by ethnic group

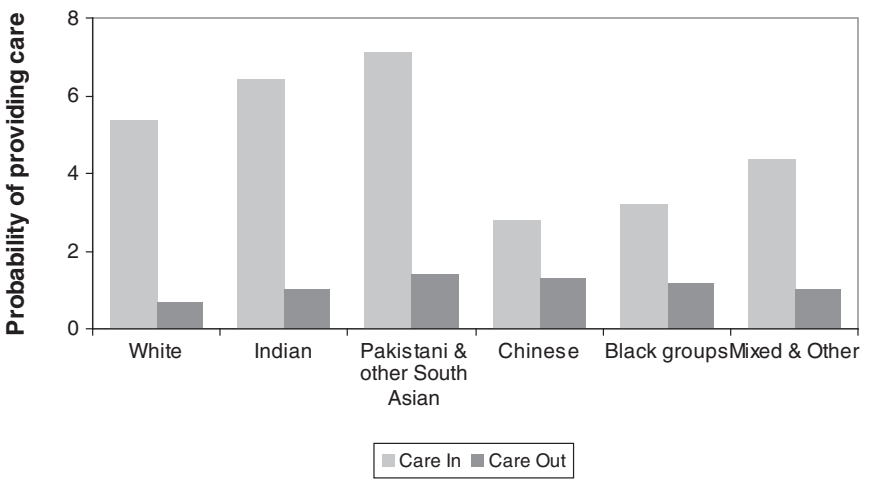

b.) Unpaid care by NS-SEC

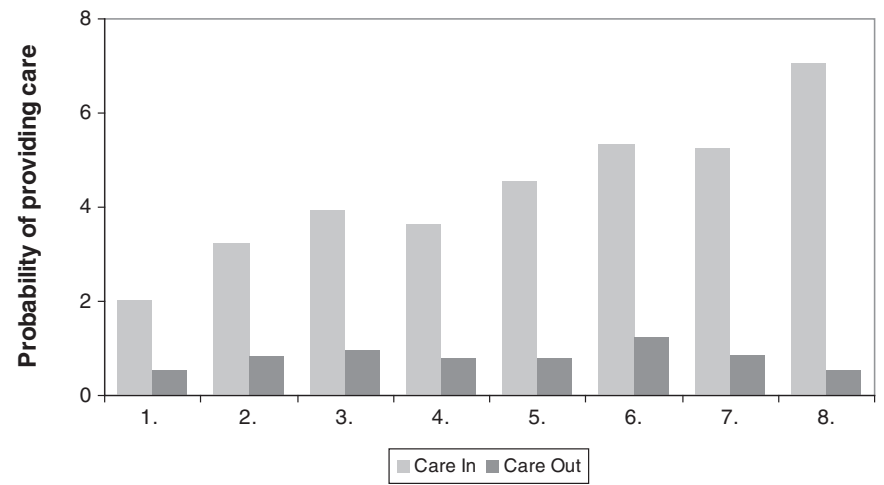

Note: NS-SEC categories

5. Lower supervisory and technical occupations

2. Lower managerial and professional occupations 6. Semi-routine occupations

3. Intermediate occupations

7. Routine occupations

4. Small employers and own account workers $\quad$ 8. Never worked and long-term unemployed

Source: Authors' calculations based on 2001 Census Small Area Microdata. The distinction between care

within and outside the household is based on whether or not the carer lived with a co-resident reporting a

limiting long-term illness

Figure 4. Modelled probabilities of unpaid caring for $20 \mathrm{~h}$ and more per week by ethnic group and National Statistics Socio-Economic Classification: England and Wales, 2001. 
We have found that unpaid caring by different ethnic groups is more complex with different patterns for care within and outside the home. To clarify the situation, we have calculated probabilities (Dale et al., 2000: 174; Boyle et al., 2002: 24) of caring by ethnic group from models 2 and 3. Figure 4(a) illustrates the probabilities (expressed as percentages) of providing $20 \mathrm{~h}$ or more per week of unpaid care differentiated by whether the care is provided within or outside the carer's household, controlling for the socio-demographic and geographic variables listed in Tables 2 and 3. For each ethnic group, more care is provided within than outside the household. For care given within the carer's home, the pattern is consistent with previous work (e.g. Young et al., 2006) with the highest probabilities shown for the South Asian ethnic groups and for the White group and lower levels of care provision by the other ethnic groups. The pattern is different when we look at care provided away from the person's household. Although the Pakistani and other South Asians still have the highest probabilities of providing care, the Chinese group are relatively active at providing care, as are the Black groups. The White ethnic group have the lowest probabilities of providing care outside the household.

Young et al. (2006) found that people of lower socio-economic status (using highest educational qualification as an indicator) were the most likely to provide unpaid care. Here, we have also investigated educational achievement and find the same pattern of provision when the care is within the household, but no clear relationship when care is away from the home. We also find contrasting patterns by NS-SEC. Figure 4(b) illustrates the probabilities of care provision derived from models 2 and 3. Consistent with educational achievement, there is an increasing probability of providing care within the home with lower occupational categories, particularly for those classified as 'never worked and long-term unemployed'. Perhaps those who are carrying out extended care are constrained from taking up employment opportunities. Although there is no clear pattern, the 'middle ground' of occupations comprises the majority of people who care away from their household. Perhaps the low levels of extended care outside the home for the highest and lowest NS-SEC categories are because the former are too busy (and can pay for others to do the caring) and the latter are tied up with caring within the home. The longitudinal analysis of the employment histories of unpaid carers of Young et al. (2006) has highlighted that those with a history of not working or with a low attachment to the labour force were the most likely to be unpaid carers.

We have found contrasting care circumstances in relation to car access and the carer's own health. Persons caring within their household are less likely to have access to a car and are more likely themselves to be of poor general health, whereas persons providing care away from their household are enabled by both car access and good general health. Maher and Green (2002) found that 39\% of unpaid carers stated that their physical or mental health was affected by their caring role. Young et al. (2006) noted that unpaid male carers are more likely to report being in poor health than women.

We have not identified any informative patterns regarding accommodation type, tenure, and living arrangements. To some extent this is because, in terms of household relationships, the SAM from the Sample of Anonymised Records does not provide enough detail on living arrangements being a file designed to allow both geographical and individual level research. The Household SARs or the ONS Longitudinal Study (as used by Young et al., 2005, 2006) are probably better sources to enable this focus.

\section{CONCLUSIONS}

Although the duty of care falls to the local authority where a person lives, unpaid caring is a crucial aspect of the social care infrastructure in England and Wales. Unpaid caring supports the welfare of family members, friends, neighbours, or others because of their long-term physical or mental health or disability, or problems relating to old age. Unpaid caring is an increasingly important issue in relation to an ageing population. As Young et al. (2006) have highlighted, the most effective framework for providing care provision and the role of institutional provision, care delivered at home, and unpaid caring is an ongoing policy challenge. Unpaid carers often have needs themselves, and their role as unpaid carers can affect their own health and well-being. A developing literature is informing how levels of illness relate to the geography of the provision of both 
formal and informal care (notably Shaw and Dorling, 2004), and about unpaid carers themselves (Dearden and Becker, 2004; Buckner and Yeandle, 2005; Young et al., 2005, 2006; Dahlberg et al., 2007; Becker and Becker, 2008).

We add to the knowledge about geographic and social variations in the amount of unpaid caring across England and Wales by differentiating between the situation within and outside the carer's own household. We find that unpaid care provided within the household relates strongly to the need for care locally. However, a proportion of the people providing unpaid care outside their own household are likely to be carrying out this activity away from their geographical area and are therefore 'commuting' to provide that unpaid care. These geographies of informal care provision can be contrasted with formal care whereby qualified nurses, midwives, and health visitors tend to live in the same geographical areas where health is poorer but medical practitioners tend to live in good health areas and commute to provide formal health care (Shaw and Dorling, 2004). As such, there may be geographical mismatches of professional carers and the demand for care meaning that there is substantial work-related commuting and/or an incorrect supply of labour. Parallel to this, our findings suggest that there are geographical variations in the location of unpaid carers and where they are providing the care. Thus, there are different geographies of health and of health care providers.

Although those people who provide unpaid care for someone within their household may face considerable demands on their time and restrictions on the use of space in their household, those people providing unpaid care to people outside their household may involve some travelling and additional resources in terms of time and financial cost. This will include how much overall care they provide. It is also likely that the demand for the unpaid caring they provide will increase as the person they care for grows older. This is an important social care policy issue, as the impact of travelling can affect the quality of care and also the health of the carer. The need to travel to care may reflect different family dispersal patterns and networks across different populations, but further research would be required in this area. As Grundy and Shelton (2001) pointed out, those people with higher educational qualifications are less likely to live near their relatives and so have less direct contact. It is also notable that recent research by Shelter (2010) highlighted that many adults are unable to look after their elderly parents because they cannot afford to live near them as a consequence of housing costs.

Our research findings have important implications for our understanding of the dynamics of caring and for service providers at a national and local level and also for government focus on independent living and individual care plans. For those unpaid carers who do not live with or even live close to the people they care for, there are different demands and potential support needs and resource implications that need to be addressed for both them and the people they care for. We must stress that the distinction between people who care within and outside their home has been estimated. Somebody who is providing unpaid care who lives with a person with a long-term health problem may also be providing care to someone else outside their own household. With the available data, we cannot capture this, so might be under-estimating levels of care provided away from the carer's own home.

Evandrou and Falkingham (2005), in their review of the impact of New Labour's approach to providing for the care of older people, highlight how, as resources become increasingly targeted at those requiring intensive support, those with moderate support needs are receiving less help and, as a result, are increasingly reliant on ad hoc help. The 'State of Social Care in England 2006-2007' (CSCI, 2008) acknowledges that the care provided across the UK varies in availability and quality. Although a carer's strategy has been published, (Department of Health, 2010a,2010b), the UK politics of health services are in something of a hiatus, given a change of government, a White Paper, and subsequent consultation on the future of the National Health Service. It is most likely that health geographies will become aligned with local authorities so the geography we use here will have relevance. When the results of the 2011 Census are released because the question we use here for 2001 has been repeated, a followup study will be informative, given growth since 2001, in the number of elderly persons who are likely to be in need of, and reliant on, unpaid care (Soule et al., 2005; Carers UK, 2009). 


\section{ACKNOWLEDGEMENTS}

This research uses Census data obtained via the Sample of Anonymised Records (SARs) support team at CCSR, a service supported by ESRC. The Census data for England and Wales have been provided by the Office for National Statistics (ONS). These data are Crown copyright and are reproduced with permission of OPSI. The authors are very grateful to the anonymous referees for their constructive and useful comments on this paper.

\section{NOTES}

(1) Note that strictly speaking, in relation to occupation, the NS-SEC classes are not ordinal (as was the Registrar General's Social Class) and that here, although differences from the reference category may be significant, differences between adjacent NS-SEC categories may not be significant.

\section{REFERENCES}

Becker F, Becker P. 2008. Young Adult Carers in the UK: Experiences, Needs and Services for Carers aged 16-24. The Princess Royal Trust for Carers in association with Young Carers International Research and Evaluation, The University of Nottingham: Nottingham.

Bono ED, Sala E, Hancock R. 2009. Older carers in the UK: are there really gender differences? New analysis of the individual sample of anonymised records from the 2001 UK Census. Health \& Social Care in the Community 17(3): 267-273

Boyle P, Norman P, Rees P. 2002. Does migration exaggerate the relationship between deprivation and limiting long-term illness? A Scottish analysis. Social Science \& Medicine 55: 21-31.

Buckner L, Yeandle S. 2005. Older Carers in the UK. Carers UK/Sheffield Hallam University: Sheffield.

Buckner L, Yeandle S. 2007. Valuing Carers - Calculating the Value of Unpaid Care. Carers UK/University of Leeds: Leeds.

Carers UK. 2009. National Carers Strategy. Care Partnership Managers. Policy Briefing. Available at: http://www.carersuk.org/professionals/resources/ briefings/

CSCI. 2008. State of Social Care in England 2006-07. Commission for Social Care Inspection: London.

Dahlberg L, Demack S, Bambra C. 2007. Age and gender of informal carers: a population-based study in the UK. Health $\mathcal{E}$ Social Care in the Community 15(5): 439-445.

Dale A, Fieldhouse E, Holdsworth C. 2000. Analysing Census Microdata. Arnold: London.
Dearden C, Becker S. 2004. Young Carers in the UK. The 2004 Report. Carers UK: London.

Department of Health. 2010a. Recognised, Valued and Supported: Next Steps for the Carers Strategy. HM Government.

Department of Health. 2010b. Prioritising Need in the Context of Putting People First: A Whole System Approach to Eligibility for Social Care Guidance on Eligibility Criteria for Adult Social Care, England 2010. Department of Health - Social Care Policy \& Innovation.

Evandrou M, Falkingham J. 2005 A secure retirement for all? Older people and new labour. In New Labour, Poverty, Inequality and Exclusion, Hills J, Stewart K (eds). Policy Press: Bristol; 167-188.

Grundy E, Shelton N. 2001. Contact between adult children and their parents in Great Britain. Environment and Planning A 33: 685-697.

Hutton S, Hirst M. 2000. Caring Relationships over Time. Social Policy Research Unit, University of York.

Maher J, Green H. 2002. Carers 2000: Results from the Carers' Module of the General Household Survey 2000. The Stationery Office: London.

Norman P. 2010. Demographic and deprivation change in the UK, 1991-2001. In Understanding Population Trends and Processes Volume 2: Spatial and Social Disparities, Stillwell J, Norman P, Thomas C, Surridge P (eds). Springer: Dordrecht; 17-35.

Norman P, Bambra C. 2007. Unemployment or incapacity? The utility of medically certified sickness absence data as an updatable indicator of population health. Population, Space \& Place 13(5): 333-352.

Shaw M, Dorling D. 2004. Who cares in England and Wales? The Positive Care Law: cross-sectional study. British Journal of General Practice 54: 899-903.

Shelter. 2010. Affordability Crisis Fractures Families. Shelter: London.

Soule A, Babb P, Evandrou M, Balchin S, Zealey L. 2005. Focus on Older People. Office for National Statistics. Palgrave/HMSO: London.

Stillwell J, Hussain S, Norman P. 2008. The internal migration propensities and net migration patterns of ethnic groups in Britain. Migration Letters 5(2): 135-150.

Vickers DW, Rees PH. 2006. Introducing the National Classification of Census Output Areas. Population Trends 125: 15-29.

Yeandle S, Bennett C, Buckner L. 2007. Carers, Employment and Services in their Local Context. Report No. 4 of Carers, Employment and Services Report Series. Carers UK/ University of Leeds.

Young H, Grundy E, Jitlal M. 2006. Care Providers, Care Receivers: A Longitudinal Perspective. Joseph Rowntree Foundation: York.

Young H, Grundy E, Kalogirou S. 2005. Who cares? Geographic variation in unpaid caregiving in England and Wales: evidence from the 2001 Census. Population Trends 120: 23-34. 